\title{
İşletmelerde Bilişim Sistemleri Uygulamaları: Demir Çelik Sektörü Örneği
}

\author{
Gülten Demirala ${ }^{*}$, Abdullah Karakaya ${ }^{b}$
}

${ }^{a}$ Karabük Üniversitesi, Sosyal Bilimler Enstitüsü, Karabük.

${ }^{b}$ Karabük Üniversitesi, İktisadi İdari Bilimler Fakültesi, Karabük.

\section{$\ddot{O} z$}

Günümüzde bilgiye ulaşma, yayma, işletme için yararlı hale getirme, bilişim sistemleri vasıtasıyla çok daha kolay gerçekleşmektedir. İşletmeler bu teknolojiler vasıtasıyla işgücü verimliliği, hızl iletişim, iş güvenliği, üretimde otomasyon, online satış alternatifi, tedarik gibi avantajlar sağlamaktadır. Bu avantajlarla işletmeler rasyonellik düzeyini artırma, performans artışı, müşteri memnuniyeti ve rekabet yeteneği kazanabilmektedirler. Bu noktada, işletmeler için önemli olan doğru bilişim sistemi temini ve bunun bilgiye dönüştürülmesidir. Çalışmada Karabük ilinde yer alan Kardemir A.Ş. demir çelik işletmesinin bilişim sistem faaliyetleri araştırılmıştır. Bu bă̆lamda söz konusu işletmenin yönetsel pozisyondaki çalışanlarıla anket uygulaması gerçekleştirilmiştir. Anket formlarında yer alan veriler frekans, yüzde ve one sample $t$ test yöntemiyle analiz edilmiştir. Sonuçlar ise söz konusu demir çelik işletmesinin bilişim sistemlerinden yararlanarak optimum fayda sağladı̆̆ını ve genel işletme performansını artırdığııı göstermektedir. Sürdürülebilir performans artışı için ise bilişim sistem teknoloji ve uygulamalarının sürekli takip edilmesi ve bu alandaki yenilikleri, gelişmeleri iş süreçlerine adapte etmeleri yerinde olacaktır.

Anahtar Kelimeler: Bilişim Sistemleri, Bilgi Teknolojileri, Strateji

\section{Information Systems Applications in Enterprises: The Case of Iron and Steel Industry}

\section{Abstract}

Today, access to information, dissemination, making it useful for business are realized much easier through IT systems. Businesses have advantages on labor productivity, faster communication, safety, automation in production, online sales and supply using these Technologies. These advantages provide the improvement of the rational level, performance improvement, customer satisfaction and competitiveness capability. At this point, the important issue for businesses is providing accurate information systems and its conversion into knowladge. In this study, information system activities of Karabük Kardemir Inc. of iron and steel factory, located in Karabük province are analyzed. In this context, a questionnaire was conducted with managers. The data were analyzed using frequency, percentage, one sample t-test method. The results indicate that iron and steel factory provides optimum benefits by the information systems and increases the overall operating performance. For sustainable increase in Performance, information systems and technology improvement must be followed and improvements must be adapted to business processes.

Keywords: Information Systems, Information Technologies, IT Strategy. 


\section{GİRIŞ}

Bilgi hızla küreselleşen dünyada işletmelerin hedeflerine ulaşabilmelerinde stratejik bir unsur haline gelmiştir. Günümüzde bilginin etkinliğini artıran bilişim sistemlerinin gelişimi işletmeleri bilişim ağıyla kuşatmıştır. Artık çoğu işletme temel iş süreçlerini dijital olarak gerçekleştirerek rekabette, müşteri memnuniyetinde, rasyonellikte etkin olmaya çalışmakta ve dijital işletmelere dönüşmeye çalışmaktadır. Çünkü bilişim sistemleri uygulamaları işletmelere hız, esneklik, tasarruf, etkin iletişim gibi birçok fayda sağlamaktadır.

Özellikle işletme yöneticileri iş süreçlerine dair kararlar verirken bilişim sistemlerinden yararlanmaktadırlar. Çünkü tam zamanında, hızlı, öz bilgi sahibi olarak yönetsel kararlar vermek daha etkili ve isabetlidir. Bu ise rasyonel çalışan bilişim sistemlerini gerekli kılar. Yani yöneticilerin etkin, etkili, teknolojik donanımlı bilişim sistemleriyle desteklenmesini gerekli kılar. Ayrıca bilişim sistemlerinin etkinliğini artırmada kalifiye işgücü yetiştirme, bu konuda çalışanlara daha yoğun eğitim, oryantasyon sağlama ve daima bilişim sistemlerini güncelleme konusunda olumlu uygulamaların geliştirilmesi gerekir.

Bilişim sistemleri uğraşı bakımından işletmeleri iki kategoriye ayırmaktadır. Birincisi; bilişim teknolojileri üretimi için gerekli faaliyetleri sürdüren işletmeler (yazılım, donanım üreten işletmeler), ki bu işletmeler için bilişim teknolojileri bir temel yetenektir. İkincisi bu yazılım, donanım vs. kullanan diğer tüm işletmelerdir. Bu işletmeler için de bilişim teknolojileri hemen her kademede ihtiyaç duyulan ve iş yapış usullerini kolaylaştıran bir yardımcı unsur niteliği taşımaktadır. Araştırmada ele alınan işletme ikinci kategoride yer almaktadır.

\section{KURAMSAL ÇERÇEVE}

Bilişim, çağımıza damgasını vurmuş olup evrim çizgisi hızlanmakta olan bir bilim ve teknoloji alanıdır (Sankur, 2004: v). Sözlük anlamılla "bilişim", "insanoğlunun teknik, ekonomik ve toplumsal alanlardaki iletişiminde kullandığ bilimin dayanağı olan bilginin özellikle elektronik makineler aracılığıyla düzenli ve akla uygun bir biçimde işlenmesi bilimi" olarak tanımlanmaktadır ve Fransızca kökeni "enformatik", "informatik" terimlerine karşılık gelmektedir (Avşar ve Öngören, 2010: 41). Enformasyon ise düzenli kullanılabilir veriler demektir (Türk, 2003: 78). Enformasyon sürecinde veriler toplanır. Toplanan bu veriler işletme için değer taşır bir hale dönüştürülebilmişse bilgi meydana gelir.

Bilişim hem verilerin işlenmesini, yani bilgi işlemi, hem de bilgi işlemin sonucunun aktarılmasını, yani veri iletişimini sağlamaktadır. Teknik, ekonomik, sosyal, hukuk ve benzeri alanlardaki verinin saklanması, saklanan bu verinin otomatik olarak işlenmesi, organize edilmesi, değerlendirilmesi ve aktarılması ile ilgili bir bilim dalıdır (Tavukçuoğlu, 2004: 55).

\subsection{Bilişim Teknolojileri}

Bilişim teknolojileri (BT) veri işleme, saklama, yayma faaliyetlerini mikro elektroniğe dayalı hesaplama ve iletişim özelliği aracılığıyla gerçekleştirebilir. BT; 
lazer, fiber optik, ses tarayıcıları gibi iletişim teknolojilerinin gelişimine paralel olarak hızla gelişmektedir (Bensghir, 1996: 39-40).

BT gelişimi ekonomilerde mevcut üretim, tüketim, birikim ve bölüşüm süreçlerini değiştirmektedir. Yeni ürün ve hizmetlerin payı toplam üretim içinde hızla artmakta, bu teknolojilere sahip olan işletmeler rekabet gücünü artırmakta, bu teknolojileri elde etme ve etkin biçimde kullanabilme yeteneği daha belirgin hale gelmekte, iş modelleri ve işgücü piyasası değişime uğramaktadır (Kalkınma Bakanlığı, 2014).

Bir işletmede ahenkli bir bilişim teknolojileri alt yapısının oluşması için yedi temel bileşenin koordine edilmesi gerekir. Bunlar; Bilgisayar donanım platformu: masa üstü bilgisayarlar, diz üstü bilgisayarlar, mobil cihazlar. Internet platformu: işletmenin genel ağ alt yapısı, donanım ve yazılım platformlarıyla örtüşmesi ve ilgili olmalıdır. Kurumsal yazılım uygulamaları: işletmenin iş yapış yöntemine uygun ideal yazılım programı seçilmelidir. Veritabanı Yönetimi ve Depolanması: verilerin düzenlenmesi, yönetilmesi, depolama alanı ve aygıtları kullanımıyla veriler güvenli biçimde saklanabilir. A $\breve{g} /$ Telekomünikasyon Yapısı: işletme içi ve dışı kişilerle iletişim ağı kurma ve yetkilendirme yapısı oluşturmalıdır. İşletim Sistemi Platformu: geleneksel işletim sistemi fare ve klavye ye ek olarak dokunmatik teknoloji de kullanılmaktadir. Danışmanlar ve Sistem Birleştiricileri: teknolojiyi etkin kullanma, eski teknolojiyi yeni bir alt yapıyla bütünleştirme konularında işletmelere küresel ve kurumsal hizmet sunumu faaliyetlerinden yararlanılarak BT etkinliği sağlanabilir (K. C. Laudon ve J. P. Laudon, 2014: 68).

\subsection{Bilişim Sistemleri}

Bilişim sistemleri (BS) bilişim teknolojilerini de içine alan daha geniş bir alandır. Bilişim sistemleri; donanım, yazılım, veri toplama ve işletmenin BT alt yapısını oluşturan ağların tamamını içine alır (K.C. Laudon ve J.P. Laudon, 2014: 175-181). Bilişim sistemleri BT teknolojisinin bir işletmede kullanılmasına yönelik strateji ve ilkeleri içerir. BT kullanımının işletme stratejileri ve hedeflerini desteklediğinden emin olmak için karar hakları ve yükümlülükler çerçevesini belirler. BT teknolojisi yatırımının geri dönüşümünü planlama da dahil olmak üzere, BT teknolojisinin etkili yönetimi ve kullanımını sağlamak için hangi kararlar alınmalıdır, bu kararlar nasıl hayata geçirilmeli ve denetlenmelidir ve kimler tarafından uygulanmalıdır soruları bilişim sistemlerinin çerçevesini oluşturur (Weill ve Ros, 2004: 76).

Bilişim sistemlerinin işletmelerde kullanımı, rutin işlerin (özlük işleri ya da standart yazışmalar gibi) otomasyonu amacıyla olmuştur. Daha sonraları işletmeler operasyonel verimliliği arttırabilmek için bilişim sistem ve teknolojilerine daha çok rağbet etmeye başlamışlardır. İlerleyen zaman hem teknolojinin, hem de iş dünyasının çehresini değiştirmiş, bilişim sistemlerine hâkim olma ve kullanabilme becerisini, ayrica bu alanda yaşanan gelişmeleri takip etme adeta bir zorunluluk olmuştur. Bu noktada da işletmeler bilişimi kendilerine rekabet avantajı yaratabilecek ve belirsizlik içerisinde yaşamlarını sürdürebilmelerini kolaylaştırabilecek bir varlık olduğunu 
anlayarak, bilişim sistemlerini stratejik bir araç olarak görmeye başlamışlardır (Acar, 2007: 16).

Günümüzde bilişim sistemleri bir işletmeye özellikle rekabet üstünlüğü sağlamada kritik rol oynamaktadır. Bilişim sistemleri alanındaki gelişmelerle birlikte bu sistemlerin lisans kullanım maliyetlerinin azalması, teknolojik altyapı ve kalifiye işgücü yetersizliğinden kaynaklanan eksikliklerin azalmasıyla birlikte gün geçtikçe daha da rasyonel hale gelmektedir. İşletmeler bilişim sistemlerini etkin bir biçimde kullanarak; verimlilik artışı sağlayabilmekte, maliyetlerini azaltabilmekte, yeni ürünler, hizmetler ve süreçler geliştirerek rakiplerine karşı üstünlük elde edebilmektedir (Tekin, Zerenler ve Bilge, 2005: 117).

\subsection{Bilişim Sistemleri Uygulamaları}

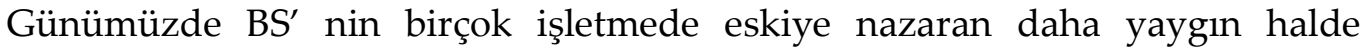
kullanımı işletmelerin yeni bir yapıya bürünmelerini gerektirmiştir. Bu sistemler bireyler tarafından yerine getirilen görevlerin türlerini, grupların yapısını, yönetimin doğal yapısını ve yöneticilerin rollerini değiştirmiştir. Örneğin; BS, emir ve otoritelerin çizgilerinde değişmelere sebep olmuş, hiyerarşik yapıyı da değiştirerek, karar verme ve kontrol sistemlerinin merkezileşmesine veya ademi merkezileşmesine yol açmıştır. (Güleş ve Özata, 2005: 71).

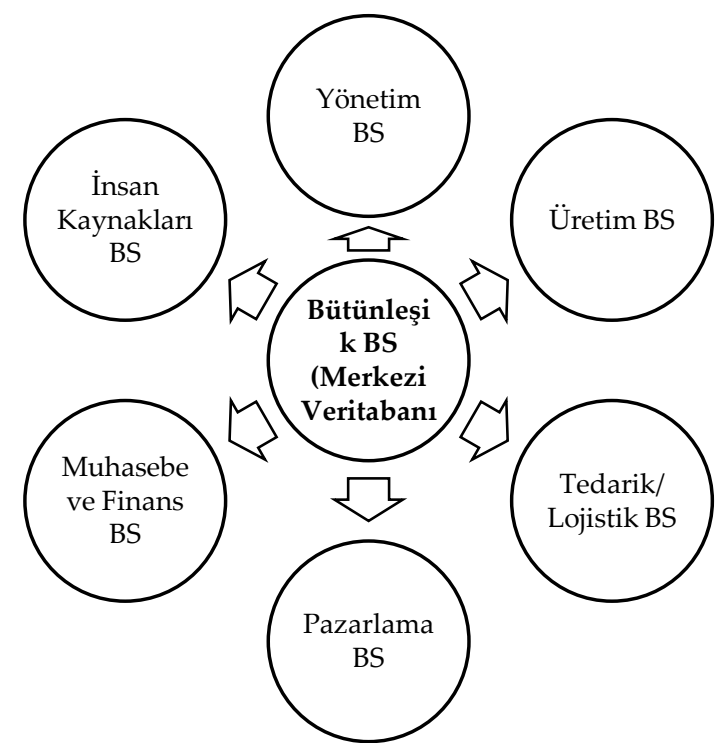

\section{Şekil 1. Bilişim Sistemleri Entegrasyonu}

Yukarıdaki şekle göre; bilişim sistemlerinin kullanımı bir işletmede iki ana kategoride değerlendirildiğinde, entegre (bütünleşik) bilişim sistemleri ve fonksiyonel bilişim sistemleri olarak ayrılabilir. Entegre (bütünleşik) bilişim sistemleri dediğimizde işletmenin bütününü içine alan bilişim bilgisini içerir. Örneğin işletmenin iş yapış yöntemine uygun yararlanabileceği bir yazılım programıdır. Fonksiyonel bilişim sisteminde ise; bir işletme de bulunan tüm departmanların bilişim ihtiyacı birbirinden farklıdır. Örneğin yazılım programının pazarlama, finans, muhasebe, insan kaynakları, ar-ge, üretim gibi işletme departmanlarına dair modülleri vardır ve her biri ayrı bilgi 
ve kullanım gerektirir. Diğer bir ifadeyle tüm fonksiyonel birimlerin kullandığı bilişim, entegre bilişim sisteminin bir parçasıdır. Üst düzey yönetici ise alacağı stratejik kararlarda makro bakış açısıyla hareket ederek bütünleşik bilişim sisteminin çıtılarından elde edilen bilgilerle karar verecektir.

\section{KARDEMİR A.Ş. ÜZERİNE BİR ARAŞTIRMA}

Kardemir A.Ş. bağlı kuruluşlarla birlikte yaklaşık 4.000 kişinin istihdam edildiği entegre bir demir çelik fabrikasıdır. Yılda ortalama 2.000.000 ton ham çelik üretmektedir. İstanbul Sanayi Odası tarafından her yıl açılanan verilere göre Türkiye'nin en büyük ilk 50 sanayi kuruluşu arasında yer almaktadır. Kardemir'in, döküm ve mekanik işleme işletmesi KARDÖKMAK A.Ş., çelik konstrüksiyon imalatı yapan KARÇEL A.Ş., hidroelektrik santrali ENBATI A.Ş. olmak üzere üç büyük bağl1 kuruluşu bulunmaktadır. Çimento sektöründe KARÇIMSA A.Ş., madencilik sektöründe ERDEMIR MADEN A.Ş. yanı sıra konvansiyonel ve yüksek hıza uygun demiryolu makasları üretmek üzere kurulan VADEMSAŞ A.Ş. ile ortaklığı bulunmaktadır (Kardemir, 2014).

\section{Araştırmanın Amacı}

$\mathrm{Bu}$ çalışma Kardemir A.Ş. bilişim sistemi uygulama yetenekleri ve işletmeye olan katkıları üzerinedir. Bu kapsamda araştırmanın alt amaçları ise şöyledir;

- Bilişim sistemlerinin işletme rasyonelliğine katkısının incelenmesi,

- Bilişim sistemlerinin müşteri memnuniyetine katkısının incelenmesi,

- Bilişim sistemlerinin rekabet edebilme düzeyine katkısının incelenmesidir.

\section{Araştırmanın Yöntemi}

Bilişim sistemi uygulama yetenekleri ve işletmeye olan katkılarının saptanmasına yönelik bu araştırmada evren Kardemir A.Ş.' de çalışan tüm fonksiyonel yöneticiler ve ayrıca bilişim sistem departmanındaki tüm çalışanlardır. Araştırmada veriler anket yöntemiyle toplanmıştır. 22 fonksiyonel yöneticiye ve 25 bilgi işlem departmanı yönetici ve çalışanlarına uygulanmıştır. Ankete katılan toplam kişi sayısı 47'dir ve evrenin tamamına ulaşılmıştır. Anket verileri uygun istatistik yöntemlerle ölçülmüştür. Anket formunun güvenilirliği ile ilgili olarak yapılan analizde Cronbach's Alpha katsayısı \%89 olarak hesaplanmıştır.

Fonksiyonel yöneticilerin bilişim sistemleri algılarına dair ölçüm 7'li likert ölçeği kullanılarak hazırlanmıştır. Anket soruları literatürde yer alan bilişim sistemleri konusunda yapılmış çalışmalardan yararlanılarak hazırlanmış ve pilot anket uygulamasının ardından son şekli verilmiştir. Ankette yöneticilerin demografik özelliklerini belirleyici 5, bilgi teknolojileri kullanım düzeyleri ve algılarını ölçen 35 sorudan oluşmaktadır. Toplamda 40 soru yöneltilmiştir. Araştırmanın hipotezleri bilişim sistemleri yetkinliğini ölçen değişkenlerle ilgili sorulardan üretilmiş olup her bir soru bir hipotez çiftine denk gelmektedir. Örneğin; birinci ve ikinci sorulara ilişkin hipotez çifti şöyledir;

- Ho: BT'nin iş süreçlerini standartlaştırmaya ve basitleştirmeye katkısı yoktur 
- $\mathrm{H}_{1}$ : BT’nin iş süreçlerini standartlaştırmaya ve basitleştirmeye katkısı vardır.

- Ho: BT uygulamaları şirket içi otomasyon sağlamada yeterli değildir.

- Hı: BT uygulamaları şirket içi otomasyon sağlamada yeterlidir.

\section{BULGULAR}

Tanımlayıcı bilgiler ile ilgili veriler frekans ve yüzdeler şeklinde değerlendirilmiştir. Fonksiyonel değişkenlere ilişkin veriler ise One-sample $t$ Test istatistiği kullanılarak analiz edilmiştir.

Tablo 1. Yöneticilerin Özellikleri

\begin{tabular}{|c|l|c|c|}
\hline Özellikleri & Dağılımı & Sayı & \% \\
\hline \multirow{4}{*}{ Cinsiyeti } & Kadın & 12 & 25 \\
\cline { 2 - 4 } & Erkek & 35 & 75 \\
\hline \multirow{5}{*}{ Görevi } & Müdür & 14 & 30 \\
\cline { 2 - 4 } & Müdür Yardımcısı & 1 & 2 \\
\cline { 2 - 4 } & Baş Mühendis & 5 & 11 \\
\cline { 2 - 4 } & Mühendis & 5 & 11 \\
\cline { 2 - 4 } & Diğer & 22 & 46 \\
\hline \multirow{5}{*}{ Deneyimi } & 5 yıl ve altı & 11 & 23 \\
\cline { 2 - 4 } & 6-10 yıl arası & 4 & 9 \\
\cline { 2 - 4 } & $11-15$ yıl arası & 8 & 17 \\
\cline { 2 - 4 } & 16 yıl ve üzeri & 24 & 51 \\
\hline \multirow{5}{*}{ Yaşı } & 25 yaş ve altı & 7 & 15 \\
\cline { 2 - 4 } & 26-40 yaş arası & 16 & 34 \\
\cline { 2 - 4 } & 41 yaş ve üzeri & 24 & 51 \\
\hline \multirow{4}{*}{ Bölümü } & Bilgi işlem bölümü & 25 & 53 \\
\cline { 2 - 4 } & Dĭ̆er bölümler & 22 & 47 \\
\hline
\end{tabular}

Tablo 1'de görüldüğ ü gibi ankete cevap verenlerin $\% 25$ kadın, $\% 75$ erkek, \%30u müdür, \%2si müdür yardımcısı, \%11i başmühendis, \%11i mühendis, \%46sı diğer, \%23ü 5 yıl ve altı deneyimli, \%9u 6-10 yıl arası, \%17si 11-15 yıl arası, \%51i 16 yıl ve üzeri, \%15i 25 yaş altı, \%34ü 26-40 yaş arası, \%51i 41 yaş ve üzeri, \%53ü bilgi işlem departmanı çalışanı, \%47si diğer departman çalışanlardan oluşmaktadır.

Bilgi teknolojileri uygulama yetenekleri ve işletmeye olan katkılarına dair bulgular, Tablo 2' de sunulmuştur. 
Tablo 2. BT Uygulama Yetenekleri

\begin{tabular}{|c|c|c|c|c|}
\hline No & Sorular & $T$ & Sonuç & $\mathbf{P}$ \\
\hline 1 & $\begin{array}{l}\text { BT iş süreçlerini standartlaştırdığını ve basitleştirdiğini } \\
\text { düşünüyorum. }\end{array}$ & 5,718 & ,000 & $\mathrm{P}<0,001^{* * *}$ \\
\hline 2 & $\begin{array}{l}\text { BT uygulamaları şirket içi otomasyon sağlamaya } \\
\text { yeterlidir. }\end{array}$ & 4,657 & ,000 & $\mathrm{P}<0,001^{* * *}$ \\
\hline 3 & $\begin{array}{l}\text { BT uygulamaları şirket içi sinerji } \\
\text { oluşturacak niteliktedir. }\end{array}$ & 3,226 & ,002 & $\mathrm{P}<0.01^{* *}$ \\
\hline 4 & $\begin{array}{l}\text { BT uygulamaları şirket dışı sinerji (tedarikçiler, } \\
\text { müşteriler, bankalar, devlet vb. ile iletişim gücü, uyum) } \\
\text { oluşturacak niteliktedir. }\end{array}$ & 3,502 & ,001 & $\mathrm{P}<0.01^{* *}$ \\
\hline 5 & $\begin{array}{l}\text { BT uygulamalarımızın şirketin proaktif (öngörülü) } \\
\text { davranmasını sağlar. }\end{array}$ & 3,375 & ,002 & $\mathrm{P}<0.01^{* *}$ \\
\hline 6 & $\begin{array}{l}\text { BT kullanımındaki öncelikli hedef işgücü tasarrufu } \\
\text { sağlamak, çalışanların verimliliğini artırmak, süreçlerde } \\
\text { iyileşmeyi ve hızı artırmak dolayısıyla rasyonelliği } \\
\text { (etkinlik, verimlilik, karlılık) yakalamaktır. }\end{array}$ & 10,608 & ,000 & $\mathrm{P}<0,001^{* * *}$ \\
\hline 7 & $\begin{array}{l}\text { BT kullanımındaki öncelikli hedef müşterilere daha iyi } \\
\text { ürün ve hizmet sunmaktır. }\end{array}$ & 6,231 & ,000 & $\mathrm{P}<0,001^{* * *}$ \\
\hline 8 & $\begin{array}{l}\text { BT kullanımının, yöneticilerin karar verme hızını } \\
\text { artırdığını ve daha kısa zamanda isabetli kararlara } \\
\text { ulaşmayı kolaylaştırdığını düşünüyorum. }\end{array}$ & 8,697 & ,000 & $\mathrm{P}<0,001^{* * *}$ \\
\hline 9 & $\begin{array}{l}\text { BT uygulamaları, doğrudan müşteri sadakatini } \\
\text { arttıracak veya bağımlılık oluşturacak niteliktedir. }\end{array}$ & 1,940 & ,058 & $\mathrm{P}>0.05^{\mathrm{ns}}$ \\
\hline 10 & $\begin{array}{l}\text { BT uygulamaları, pazarlanabilir yeni ürün } \\
\text { he } \\
\text { hizmetlerin oluşturulmasına doğrudan katkı sağlar. }\end{array}$ & 3,402 & ,001 & $\mathrm{P}<0.01^{* *}$ \\
\hline 11 & $\begin{array}{l}\text { Başarılı olabilmek, pazarda rekabet } \\
\text { yakalayabilmek ya da yürüttüğü işlerde } \\
\text { performansek } \\
\text { en önemli başarı faktörün bilişim sistem stratejileridir. }\end{array}$ & 4,292 & ,000 & $\mathrm{P}<0,001^{* * *}$ \\
\hline 12 & $\begin{array}{l}\text { Bilgi teknolojileri uygulamalarımızın, mevcut ve olası } \\
\text { rakipler için oyunun kurallarını değiştirecek nitelikte } \\
\text { olduğunu düşünüyorum. }\end{array}$ & ,353 & ,726 & $\mathrm{P}>0.05^{\mathrm{ns}}$ \\
\hline 13 & $\begin{array}{l}\text { BT uygulamaları, olası rakipler için pazara giriş engeli } \\
\text { oluşturacak niteliktedir. }\end{array}$ & ,423 & 675 & $\mathrm{P}>0.05^{\mathrm{ns}}$ \\
\hline 14 & $\begin{array}{l}\text { BT uygulamaları, rekabeti fiyat rekabetinden ürün } \\
\text { farklılaşmasına çevirecek niteliktedir. }\end{array}$ & ,455 & 651 & $\mathrm{P}>0.05^{\mathrm{ns}}$ \\
\hline 15 & $\begin{array}{l}\text { BT uygulamaları, tedarikçilerle daha yakın ilişki } \\
\text { sağlayacak niteliktedir. }\end{array}$ & 3,630 & ,001 & $\mathrm{P}<0.01^{* *}$ \\
\hline 16 & BT kullanımı veri güvenliğini artırır. & 5,318 & ,000 & $\mathrm{P}<0,001^{* * *}$ \\
\hline 17 & BT kullanımı iş sağlığı ve güvenliğini artıırı. & 2,607 & 012 & $\mathrm{P}<0,01^{*}$ \\
\hline 18 & BT kullanımı, veri işleme kapasitesini artırır. & 5,905 & 000 & $\mathrm{P}<0,001^{* * *}$ \\
\hline 19 & $\begin{array}{l}\text { BT kullanımı yoğun ve gereksiz bilgiye maruz bırakır, } \\
\text { süreci karmaşıklaştırır ve prosedürleri artırır. }\end{array}$ & $-3,587$ & ,001 & $\mathrm{P}<0,01^{* *}$ \\
\hline 20 & $\begin{array}{l}\text { BT etkinliği için çalışanlara yeterli eğitim ve } \\
\text { oryantasyon (işe uyum) sağlanır. }\end{array}$ &,- 781 & 439 & $\mathrm{P}>0.05^{\mathrm{ns}}$ \\
\hline
\end{tabular}


Tablo 3. BT Uygulama Yetenekleri (Devami)

\begin{tabular}{|c|c|c|c|c|}
\hline No & Sorular & $T$ & Sonuç & $\mathbf{P}$ \\
\hline 21 & $\begin{array}{l}\text { BT yenilikleri işletme kültürüne uyumlaştırmada çok az } \\
\text { problem yaşanır. }\end{array}$ &,- 911 & ,367 & $\mathrm{P}>0.05^{\mathrm{ns}}$ \\
\hline 22 & $\begin{array}{l}\text { Şirket yönetimi BT yeniliklerini sürekli takip eder ve bu } \\
\text { alandaki teknolojik yatırımları sürekli günceller. }\end{array}$ & 2,944 & ,005 & $\mathrm{P}<0,01^{* *}$ \\
\hline 23 & $\begin{array}{l}\text { Departmanlarda kullanılacak olan verinin biçimine } \\
\text { yönelik olarak ihtiyaç analizleri yapılır. BT'in başarıya } \\
\text { katkıda bulunabileceği noktaları ya da } \\
\text { destekleyebileceği alanlar tespit edilir. }\end{array}$ & $-2,647$ & -011 & $\mathrm{P}<0,01^{*}$ \\
\hline 24 & $\begin{array}{l}\text { Geliştirilecek BS ve gereksinim duyulacak } \\
\text { altyapısına ilişkin olarak maliyet analizleri yapılır. }\end{array}$ & $-3,027$ & ,004 & $\mathrm{P}<0,01^{* *}$ \\
\hline 25 & $\begin{array}{l}\text { BT'nin işletmenin uzun vadeli stratejik amaçlarına } \\
\text { ulaşmasına yönelik desteği ve bunun şekli ile ilgili } \\
\text { alternatif senaryolar üretilir. }\end{array}$ & $-1,707$ & ,095 & $\mathrm{P}>0.05^{\mathrm{ns}}$ \\
\hline 26 & $\begin{array}{l}\text { İşletmemizin, mevcut ya da ileride yatırım yapmayı } \\
\text { düşündüğü BT detaylı bir şekilde belirlenmiş ve } \\
\text { belgelendirilmiştir. }\end{array}$ & $-4,873$ & , 000 & $\mathrm{P}<0,001^{* * *}$ \\
\hline 27 & BT verimliliği devamlı ölçülür. & $-3,511$ & ,001 & $\mathrm{P}<0,01^{* *}$ \\
\hline 28 & $\begin{array}{l}\text { BT'nin geçmişteki kullanımına yönelik olarak sergilemiş } \\
\text { olduğu performanslar (başarılı / başarısız) gözden } \\
\text { geçirilir. }\end{array}$ & $-4,885$ & , 000 & $\mathrm{P}<0,001^{* * *}$ \\
\hline 29 & $\begin{array}{l}\text { BT'nin yaratabileceği rekabet/performans avantajları } \\
\text { belirlenir. }\end{array}$ & $-5,227$ & , 000 & $\mathrm{P}<0,001^{* * *}$ \\
\hline 30 & $\begin{array}{l}\text { Mevcut BT altyapısı; işlevsellik, performans ve } \\
\text { teknolojinin organizasyon içerisindeki gelişimi gibi } \\
\text { çeşitli kriterler açısından analiz edilir ve yetersiz olduğu } \\
\text { durumlar tespit edilir. }\end{array}$ & $-3,704$ & ,001 & $\mathrm{P}<0,01^{* *}$ \\
\hline 31 & $\begin{array}{l}\text { Faaliyet gösterilen sektörde ve diğer sektörlerde BT } \\
\text { kullanımının ne amaçla ve hangi şekilde gerçekleştiği } \\
\text { analiz edilir. }\end{array}$ & $-4,508$ & ,000 & $\mathrm{P}<0,001^{* * *}$ \\
\hline 32 & $\begin{array}{l}\text { İşletmede, BT'nin etkin ve verimli kullanımı için } \\
\text { yetişmiş eleman ve personel yetersizliği / eksikliği } \\
\text { önemli bir durum teşkil etmektedir. }\end{array}$ & $-8,296$ & ,000 & $\mathrm{P}<0,001^{* * *}$ \\
\hline 33 & BT yatırımları yüksek maliyetlidir. & $-8,489$ & ,000 & $\mathrm{P}<0,001^{* * *}$ \\
\hline 34 & BT için katlanılan maliyet kısa sürede kara dönüşmez. & $-6,296$ & ,000 & $\mathrm{P}<0,001^{* * *}$ \\
\hline 35 & $\begin{array}{l}\text { Bilgisayar donanım ve yazılımında her zaman son } \\
\text { teknoloji takip edilir ve bu yönde yapılan yatırımlar } \\
\text { önemli bir yer tutar. }\end{array}$ & $-4,097$ & 000 & $\mathrm{P}<0,001^{* * *}$ \\
\hline
\end{tabular}

Tabloda görüldüğü gibi bilgi teknolojileri (BT) araştırmaya konu olan işletmeye; iş süreçlerinde standartlaştırma, şirket içi otomasyon, işgücü tasarrufu, işgücü verimliliği, süreçlerde iyileştirme gibi avantajlar sağlamaktadır. BT uygulamalarının veri güvenliğini, veri işleme kapasitesini artırdığı düşünülmektedir. İşletme, BT stratejilerini yüksek performans sergileyebilmede önemli bir başarı faktörü olarak görmektedir. İşletmenin mevcut ya da ileride yatırım yapmayı düşündüğ̈̈ BT alanlarının detaylı bir şekilde belirlediği ve belgelendirdiği, BT'nin geçmişteki kullanımına yönelik 
olarak sergilemiş olduğu performansların (başarılı/başarısız) gözden geçirildiği anlaşılmaktadır. BT'nin yaratabileceği rekabet/performans avantajlarının belirlendiği, faaliyet gösterilen sektörde ve diğer sektörlerde BT kullanımının ne amaçla ve hangi şekilde gerçekleştiğinin analiz edildiği de araştırmada elde edilen bulgular arasındadır. Yanı sıra BT kullanımının yöneticilerin karar verme hızını artırdı ̆̆ı, kısa zamanda isabetli kararlara ulaşmayı kolaylaştırdığı anlaşılmaktadır. Yukarıda sayılan maddeler Kardemir A.Ş. demir çelik işletmesi yöneticilerin ortak düşünceleri olup, bu konuların istatistiki açıdan onlar için ileri düzeyde anlamlı olduğu anlaşılmaktadır $\left(\mathrm{P}<0,001^{* * *}\right)$. Ho hipotezleri reddedilmiştir.

Fakat BT'nin olumsuz ya da eksik olduğu düşünülen bir takım noktalarının mevcudiyetinden de bahsetmek mümkündür. Alınan cevaplara göre BT nin etkin ve verimli kullanımı için kalifiye personel eksikliğinin önemli bir durum teşkil ettiği söylenebilir. Ayrıca BT yatırımlarının yüksek maliyetli olduğu, BT için katlanılan maliyetin kısa sürede kara dönüşmediği, bilgisayar donanım ve yazılımında her zaman son teknolojinin takip edildiği için ve bu yönde yapılan yatırımlar önemli bir yer tuttuğu için maliyet artışına neden olduğu söylenebilir. Bu durumlar Bilişim Sistemlerinin söz konusu işletmedeki dezavantajlı yönleri arasında yer almaktadır ve istatistiki açıdan ileri düzeyde anlamlı bulunmuştur $\left(\mathrm{P}<0,001^{* * *}\right)$. $\mathrm{H}_{1}$ hipotezleri reddedilmiştir.

BT uygulamalarının Kardemir A.Ş. de şirket içi sinerji (takım ruhu) oluşturacak nitelikte olduğu, şirket dışı sinerji (tedarikçiler, müşteriler, bankalar, devlet vb. ile iletişim gücü, uyum) oluşturacak nitelikte olduğu, şirketin proaktif (öngörülü) davranmasını sağladığı, pazarlanabilir yeni ürün ve hizmetlerin oluşturulmasına doğrudan katkı sağladığı, tedarikçilerle daha yakın ilişki sağlayacak nitelikte olduğu anlaşılmaktadır. Şirket yönetiminin BT yeniliklerini sürekli takip ederek bu alandaki teknolojik yatırımları sürekli güncellediği, geliştirilecek BS ve gereksinim duyulacak BT altyapısına ilişkin olarak maliyet analizleri yapıldığı, BT verimliliğinin devamlı ölçüldüğü, mevcut BT altyapısının (işlevsellik, performans ve teknolojinin organizasyon içerisindeki gelişimi gibi) çeşitli kriterler açısından analiz edildiği ve yetersiz olduğu durumların tespit edildiğine dair ifadeler yöneticilerin ortak düşünceleri olup, bu konuların istatistiki açıdan onlar için çok anlamlı olduğu anlaşılmaktadır $\left(\mathrm{P}<0,01^{* *}\right)$. $\mathrm{H}_{0}$ hipotezleri reddedilmiştir.

Fakat BT kullanımının bazen yoğun ve gereksiz bilgiye maruz bıraktığı, süreci karmaşıklaştırıp, prosedürleri artırdığı da yine cevaplayıcılardan elde edilen bulguların değerlemesidir ve istatistiki açıdan çok anlamlı bulunmuştur $\left(\mathrm{P}<0,01^{* *}\right)$. $\mathrm{H}_{1}$ hipotezleri reddedilmiştir.

BT kullanımı iş sağhlğ̆ı ve güvenliğini artırdığı, departmanlarda kullanılacak olan verinin biçimine yönelik olarak ihtiyaç analizleri yapıldığı, BT'nin başarıya katkıda bulunabileceği noktaların ya da destekleyebileceği alanların tespit edildiğine dair ifadeler düşük düzeyde anlamlı bulunmuştur $\left(\mathrm{P}<0,01^{*}\right)$. Ho hipotezleri reddedilmiştir.

Bunun yanı sıra BT uygulamalarının, doğrudan müşteri sadakatini arttıracak veya bağımlılık oluşturacak nitelikte olduğu, BT uygulamalarının, mevcut ve olası 
rakipler için oyunun kurallarını değiştirecek nitelikte olduğu, olası rakipler için pazara giriş engeli oluşturacak nitelikte olduğu, rekabeti fiyat rekabetinden ürün farklılaşmasına çevirecek nitelikte olduğu, BT etkinliği için çalışanlara yeterli eğitim ve oryantasyon (işe uyum) sağlandığı, BT yenilikleri işletme kültürüne uyumlaştırmada çok az problem yaşandığı̆, BT'nin işletmenin uzun vadeli stratejik amaçlarına ulaşmasına yönelik desteği ve bunun şekli ile ilgili alternatif senaryolar üretildiği şeklinde yöneltilen cevaplara olumlu yönde görüş bildirilmemiştir. İstatistiksel açıdan da anlamlı bulunmamıştır $\left(\mathrm{P}>0.05^{\text {ns }}\right)$. Hı hipotezleri reddedilmiştir.

\section{SONUÇ}

Kardemir A.Ş. bilişim sistemi uygulama yeteneklerini ve işletmeye olan katkılarını incelemeyi amaçlayan bu çalışmada bilişim sistemlerinin işletme rasyonelliğine, rekabet düzeyine etkisi ve müşteri memnuniyetine katkısı araştırılmıştır. Bu kapsamda araştırma verileri yedili likert ölçeğinin puan aralıklarına göre belirlenen düzeylerle derecelendirilerek analiz edilmiştir.

BS nin araştırmaya konu olan işletmeye iş süreçlerini standartlaştırma ve basitleştirme, iş gücü tasarrufu, veri güvenliği, yöneticilerin karar verme hızını artırma, şirket içi ve dişı sinerji oluşturma, şirketin proaktif davranmasını sağlama, tedarikçilerle yakın ilişki sağlama gibi avantajlar sağladı̆̆ı anlaşılmıştır.

Araştırma kapsamında incelenen değişkenlere ilişkin sonuçlar bir bütün olarak değerlendirildiğinde; araştırmaya konu olan işletmeye rasyonellik (etkinlik, verimlilik, karlılık) sağlama, ve müşteri memnuniyeti sağlama açısından BS nin ileri düzeyde yararlı olduğu görülmektedir. Fakat Bilişim Sistemlerinin Kardemir A.Ş. nin rekabet edebilme düzeyine katkısı olmadığı anlaşılmıştır.

İşletmede Bilişim Sistemi stratejileri geliştirme ve bu stratejileri adım adım belirleme, BS uygulamalarını yalınlaştırma, bu alanda kalifiye işgücü yetiştirme yani çalışanlara yeterli eğitim ve oryantasyon sağlamaya ağırlık verilmesi yararlı olacaktır.

\section{KAYNAKÇA}

Acar, G. (2007). Enformasyon Sistemlerinin Stratejik Olarak Planlanmasına İlişkin Bir Araştırma, Yök web sitesi: Yayınlanmış doktora tezi.

Anameriç, H. (2005). 'Yönetim Bilgi Sistemlerinin Yönetim Fonksiyonları Üzerinde Etkisi'http://eprints.rclis.org/11107/1/yonetim_bilgi_sistemlerinin.pdf

Avşar, Z. ve Öngören, G. (2010). Bilişim Hukuku, İstanbul: Pasifik Ofset Yayın No: 270.

Bensghir, T. K. (1996). Bilgi Teknolojileri ve Örgütsel Değiş̧im, Ankara: TODAİ Yayın No: 274.

Güleş, H. K. ve Özata, M. (2005). Sağlık Bilişim Sistemleri, İstanbul: Nobel Yayın.

http://www.kardemir.com/Yonetim.aspx?Sec=Sirket\&Ani=\&Lng=trTR\&W=4 (31.01.2015).

Laudon, K. C. ve Laudon, J. P. (2014). Yönetim Bilişim Sistemleri: Dijital İşletmeyi Yönetme, Çev.: U. Yozgat. İstanbul: Nobel Yayın. 
Sangül, M. (2013). Bilişim Teknolojileri ve Yazılım Ders Kitabı, http://mebk12.meb.gov.tr/meb_iys_dosyalar/06/01/705941/dosyalar/2013_11/08124803_biliimte knolojileriveyazlm.pdf

Sankur, B. (2004). Bilişim Sözlü̆̆̈̈, şehir: Pusula Yayın No: 90

Tavukçuoğlu, C. (2004). Bilişim Terimleri Sözlü̆̆̈̈, Ankara: Asil Yayın, Birinci Baskı.

T.C. Kalkınma Bakanlığı (2014, Mayıs) 2014-2018 Bilgi Toplumu Stratejisi ve Eylem Planı (Taslak) http://www.bilgitoplumu.gov.tr. (27 Ekim 2014)

Tekin, M., Zerenler, M. ve Bilge, A. (2005). “Bilişim Teknolojileri Kullanımının İşletme Performansına Etkileri: Lojistik Sektöründe Bir Uygulama" İstanbul Ticaret Üniversitesi Fen Bilimleri Dergisi 4 (8), 115-129.

Türk, M. (2003). Küreselleşme Sürecinde İşletmelerde Bilgi Yönetimi, İstanbul: Türkmen Kitabevi.

Weill, P. Ve Ross, J. (2009). 'IT Savvy: What Top Executives Must Know to Go from Paint to Gain" Harward Business School Press: Boston. 